\title{
El rol de las clínicas jurídicas en la promoción de los ODS en Colombia
}

\author{
Recibido: 5 de noviembre de 2019 • Aprobado: 23 de mayo de 2020 \\ https://doi.org/10.22395/ojum.v20n42a2
}

\author{
Erika Castro-Buitrago \\ Universidad de Medellín, Medellín, Colombia \\ ecastro@udem.edu.co \\ https://orcid.org/0000-0002-0467-0031
}

Juliana Vélez-Echeverri

Centro Latinoamericano de Estudios Ambientales (Celeam), Armenia, Colombia

jvelez@celeam.org

https://orcid.org/0000-0003-1072-8436

Mauricio Madrigal-Pérez

Institución Universitaria de Envigado, Envigado, Colombia

Centro Latinoamericano de Estudios Ambientales (Celeam), Armenia, Colombia

mao.madrigalp@gmail.com

https://orcid.org/0000-0002-3111-7936

\section{RESUMEN}

La Agenda 2030 que integra los objetivos de desarrollo sostenible (ODS) propone, por medio del ODS 4, la educación para el desarrollo sostenible como uno de los pilares para lograr sociedades justas, equitativas, incluyentes y en armonía con la naturaleza. En ese marco, la formación jurídica clínica es un modelo inspirador para el fortalecimiento de la educación para el desarrollo sostenible en el país. Este trabajo presenta los resultados de una investigación de tipo documental sobre el trabajo de las clínicas jurídicas colombianas en el trámite de casos reales. Se toman como referencia algunos ejemplos de la labor de las clínicas en el mundo a fin presentar la correspondencia de la agenda global clínica y de la Agenda 2030. Entre los hallazgos se reconoce el papel relevante de las clínicas colombianas como actores que promueven la sostenibilidad en el país desde un enfoque integrado del trabajo en el marco de los ODS bajo el valor de la justicia social como fundamento de sus fines pedagógicos y de proyección social.

Palabras clave: clínicas jurídicas; educación para la sostenibilidad; objetivos de desarrollo sostenible; justicia social; formación jurídica; derecho. 


\section{The Role of the Legal Clinics in the Promotion Of The SDGs in Colombia}

\section{ABSTRACT}

The 2030 Agenda integrates the Sustainable Development Goals (SDGs) through the SDG 4, quality education. The '2030 Agenda' proposes education for sustainable development as one of the pillars to achieve just, equitable, inclusive societies and in harmony with nature. Within this framework, legal clinic training is an inspiring model for strengthening education for sustainable development in the country. This paper presents the results of documentary research on real work cases of legal clinics in Colombia. In addition, it analyzes the work of various legal clinics across the world in order to explain the correspondence between the global legal clinic agenda and the 2030 Agenda. The paper finds that Colombian legal clinics play a relevant role in promoting sustainability through their integration in the SDG framework, having social justice at the core of their pedagogic goals and social projection.

Keywords: legal clinics; education for sustainability; sustainable development goals; social justice; legal education; law. 


\section{INTRODUCCIÓN}

Este artículo presenta resultados parciales del estado del arte del proyecto de investigación Enjambre ODS: educación, innovación e investigación para el desarrollo sostenible regional, financiado por el Ministerio de Ciencia Tecnología e Innovación y finalizado en el segundo semestre de 2020. Participaron la Institución Universitaria de Envigado, entidad ejecutora, en alianza con el Centro Latinoamericano de Estudios Ambientales (Celeam) en calidad de coinvestigadores.

La clínica como "embrión" de una manera de aprender y luego de enseñar se ubica a finales del siglo XVIII en el origen de la medicina como práctica liberal formalizada. De acuerdo con el estudio de Foucault (1989, pp. 68-83), el nacimiento de la clínica se presenta en la reorganización de los saberes tradicionales, la necesidad de la enseñanza de la teoría en las universidades y de su formalización para evitar los abusos de los "charlatanes" a la comunidad. En el trabajo de Foucault se relata el tortuoso camino que ha recorrido la formación médica. Desde sus orígenes, la relación entre la enseñanza teórica y la práctica de la medicina entró en conflicto acerca de la decisión sobre la prevalencia de los textos o del contacto directo con el enfermo y el servicio social que presta. La cuestión para destacar es que la clínica ha estado vinculada desde siempre a la experiencia y a la función que presta en el aprendizaje. En este sentido, Foucault (1989) afirma:

Durante mucho tiempo, sin duda, la experiencia médica permaneció abierta, y supo encontrar, entre el ver y el saber, un equilibrio que la protegió del error: "En los tiempos remotos, el arte de la medicina se enseñaba en presencia de su objeto y los jóvenes aprendían la ciencia médica en el lecho del enfermo"; estos con mucha frecuencia, estaban alojados en el domicilio mismo del médico, y los alumnos acompañaban a los maestros, mañana y tarde, a la visita de sus clientes. (p. 86)

Incluso, en la actualidad, una discusión muy similar se mantiene en la educación médica clínica que se basa en el "método interactivo entre alumno o residenteenfermo-médico" y la formación especializada en tecnologías médicas que aleja al médico del contacto directo con su paciente (Aguirre, 2010, p. 47). En el mismo sentido, en otras disciplinas que han asumido la enseñanza y aprendizaje clínico, como el derecho, se identifica la discusión sobre la prevalencia o el equilibrio de la formación teórica y la práctica. Así sucedió en los inicios de la clínica en Estados Unidos. En esta discusión es reconocido el escrito de Jerome Frank (1933), titulado ¿Por qué no un abogado-clínico?, como reacción a la enseñanza teórica de casos en la Escuela de Harvard en el que se alude a la formación en las facultades de medicina.

Esta referencia inicial a la historia de la clínica, como expresión proveniente de la medicina, tiene la intención de resaltar que el término ha involucrado desde sus inicios la cuestión sobre la importancia de la educación práctica, el contacto con la realidad y su justo equilibrio con la teoría, en la medida en que siempre debe ser 
su objetivo lograr una impresión significativa en quien aprende y tener como fin la sociedad a quien le sirve.

La educación clínica del derecho aspira a formar a los estudiantes en la práctica profesional a partir del conocimiento de casos reales, lo que implica un compromiso con el conocimiento de los problemas sociales y la formulación de soluciones. En este sentido, afirma Bloch (2013): "Las clínicas son también el lugar en donde los estudiantes aprenden sobre la comunidad local y sus necesidades jurídicas, y sobre cómo el derecho y los abogados pueden abordar estas necesidades" (p. 44).

En otras palabras, las clínicas jurídicas son ese espacio en el que docentes, estudiantes y comunidades abordan diversos problemas sociales para proponer soluciones que van más allá del ámbito de las disputas individuales a fin de alcanzar cambios en la manera en que se formula, se interpreta y aplica el derecho. De esta manera, se han convertido en un movimiento global por la justicia social que enfrenta las necesidades e intermedia en su solución.

En este sentido, la historia de la enseñanza clínica posee una importante relación con la educación para la sostenibilidad (en adelante EDS), dado que su fin ha sido poner de presente la importancia de la imprescindible relación entre la enseñanzaaprendizaje y la realidad social, lo cual no difiere de la relación con los asuntos que interesan a la sostenibilidad. En consecuencia, el propósito de este artículo es revisar el trabajo de las clínicas jurídicas y su relación con los asuntos de la sostenibilidad a fin de comprobar la hipótesis sobre su relevancia como actores claves para la promoción de los objetivos de desarrollo sostenible (en adelante ODS) en el país y, con ello, como verdaderas mediadoras de la justicia social.

La investigación base que sustenta este trabajo es cualitativa con implementación de la técnica del análisis documental. En un primer momento, se llevó a cabo un trabajo exploratorio y descriptivo de los objetivos, tendencias de la EDS y su relación con los ODS. En un segundo momento, se abordó el análisis de diferentes documentos, entre ellos artículos, capítulos, libros y páginas web de las clínicas jurídicas. Estas fuentes de información fueron fundamentales para establecer y describir el contenido y el alcance del trabajo clínico en el ámbito de la sostenibilidad y el cumplimiento de los ODS. Este análisis permitió integrar el campo del trabajo práctico de la enseñanza clínica con los propósitos de la EDS y establecer sus relaciones y aportes.

En lo que sigue de este trabajo, el estudio se concreta en una explicación general de la EDS, la revisión del trabajo de las clínicas jurídicas en el mundo y su vínculo con la EDS, concretamente los temas de trabajo que guardan relación con los ODS. Luego se examina la agenda actual de las clínicas jurídicas colombianas y su relevancia en la búsqueda de las metas de los ODS. Especialmente, se revisan las clínicas que se 
declaran de derechos humanos o de interés público', debido a que su ámbito de acción tiene mayor vínculo con el cumplimiento de ODS, como asuntos objeto de trabajo de enseñanza y aprendizaje de este tipo de clínicas.

\section{EDUCACIÓN PARA EL DESARROLLO SOSTENIBLE (EDS)}

Si se asume, como lo hace la Unesco (2012), que "la EDS involucra mucho más que sólo [sic] enseñar el conocimiento y los principios relacionados con la sostenibilidad. En su sentido más amplio, la EDS consiste en educar para generar la transformación social con el objetivo de crear sociedades más sostenibles" (p. 34), entonces es coherente y pertinente una formación basada en la solución de problemas reales que permitan la transformación del contexto en el que se vive. A su vez, esta organización internacional ${ }^{2}$ reconoce que esta modalidad de educación es parte de una educación de calidad y, por ello, se vincula con el contenido, entorno y resultados del aprendizaje (Unesco, 2019).

El origen de la EDS se enmarca en la educación para el desarrollo3 ${ }^{3}$ descrita por Mesa (2000) como "un proceso educativo constante, que favorece la comprensión sobre las interrelaciones económicas, políticas, sociales y culturales entre el Norte y el Sur" (p. 23). Y se complementa y retroalimenta con: i) la educación ambiental, en la medida en que ambas cuentan con una matriz común, esto es, la conservación del ambiente y el bienestar humano (Alba, 2017); y ii) la educación para la ciudadania global, por su relacionamiento con la democracia (Mesa, 2019).

En esencia, la EDS pretende armonizar cada una de las denominaciones ligadas al desarrollo justo, equitativo y en paz para lograr un futuro sostenible. Por ello, se proyecta desde la Agenda 2030 de las Naciones Unidas como uno de los pilares transversales para lograr el cumplimiento efectivo de los ODS.

Uno de los aspectos más relevantes para abordar la materialización y profundidad de la EDS es la aproximación conceptual sobre la sostenibilidad que se desarrolle.

1 Debe entenderse el interés público como un concepto dinámico que ha pasado de identificarse solo con el interés estatal a una noción más amplia en la que se incluye el interés ciudadano por hacer parte de importantes discusiones, antes reservadas únicamente a los gobernantes. En este sentido, González (2004) afirma: "Ya no se trata de que los actores no-estatales se limiten a participar 'desde fuera', sino que se asume que ellos intervienen y participan de forma permanente y significativa en el juego democrático, a través de sus múltiples manifestaciones" (pp. 36-37).

2 La Unesco, además de liderar el decenio de la EDS (2005-2014), coordina el Programa de Acción Mundial para la EDS a partir de dos objetivos centrales: i) reorientar la educación y el aprendizaje para que todos puedan adquirir conocimientos, habilidades, valores y actitudes que los empoderen y les permitan contribuir a un futuro sostenible; y ii) fortalecer la educación y el aprendizaje en todas las agendas, programas y actividades que promuevan el desarrollo sostenible (Unesco, 2019).

3 Mesa (2000, pp. 3-22) describe cinco generaciones de la ED: la primera generación es el enfoque caritativo-asistencia; la segunda generación, el enfoque desarrollista y la aparición de la educación para el desarrollo; la tercera generación, una educación para el desarrollo crítica y solidaria; la cuarta generación, la educación para el desarrollo humano y sostenible; y la quinta generación, la educación para la ciudadanía global. 
Alba (2017) señala que es fundamental definir esa aproximación. En términos generales, define si se habla de sostenibilidad débil, en la cual los temas ambientales se entienden incorporados al sistema económico, o sostenibilidad fuerte, en la que se intenta que la economía siga las leyes naturales (Alba, 2017, p. 17). Lo interesante es que en esa relación entre la dimensión ambiental y económica, "la dimensión social es la que determina las reglas del juego por medio del conjunto de relaciones que reflejan los valores, creencias y capacidades de los seres humanos y sus organizaciones e instituciones" (Alba, 2017, p. 17).

En todo caso, con miras a integrar las tres dimensiones de la sostenibilidad, la formulación de los diecisiete ODS (figura 1) y sus ciento sesenta y nueve metas fue el logro más importante de la Agenda 2030 aprobada por ciento noventa y tres Estados reunidos en la Asamblea General de las Naciones Unidas en el mes de septiembre de 2015 (Naciones Unidas, 2015). Se trata de una hoja de ruta para los próximos quince años, como una "una agenda transformadora, que pone a la igualdad y dignidad de las personas en el centro y llama a cambiar nuestro estilo de desarrollo, respetando el medio ambiente" (Cepal, 2018, p. 7).

Figura 1. Los diecisiete objetivos de desarrollo sostenible
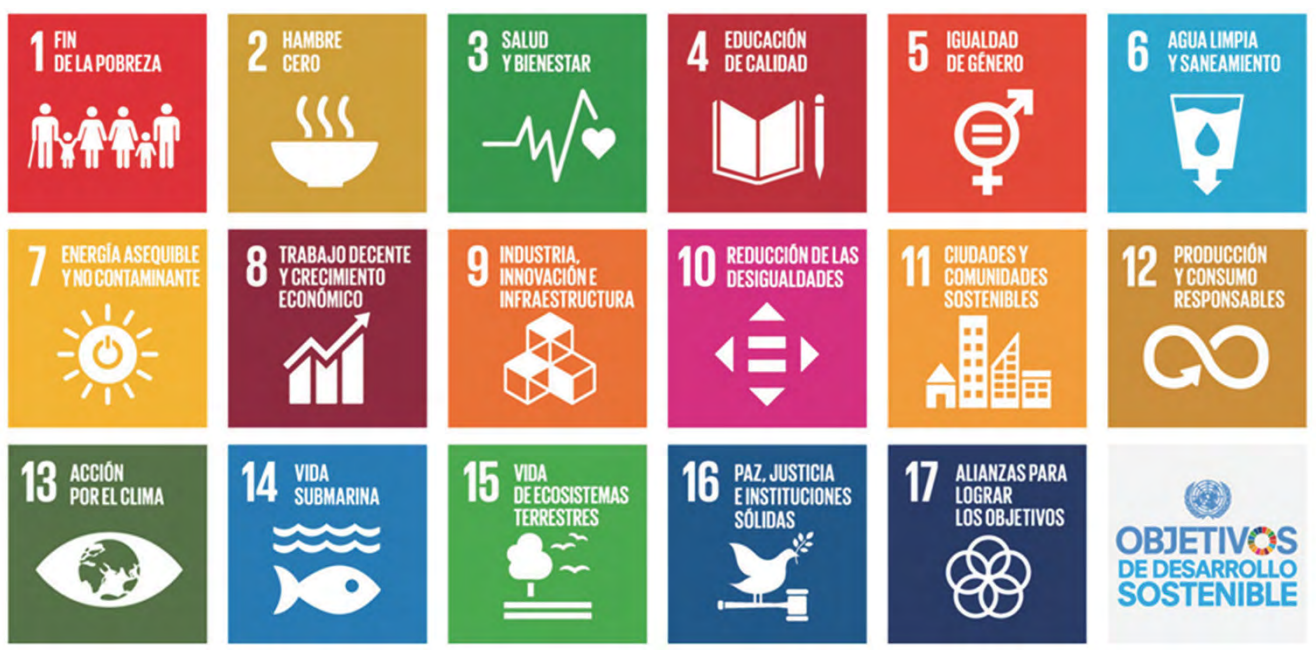

Fuente: Fondo Internacional de Desarrollo Agrícola (2020).

La Agenda 2030 reitera el compromiso de "proporcionar una educación de calidad, inclusiva e igualitaria a todos los niveles de enseñanza" (Naciones Unidas, 2015, p. 8). Para lograr la materialización de ese deber establece el ODS 4: "Garantizar una educación inclusiva y equitativa de calidad y promover oportunidades de aprendizaje permanente para todos" (Naciones Unidas, 2015, p. 16). Para ello, propone siete metas y tres submetas relacionadas con la calidad; el acceso e inclusión en la 
enseñanza prescolar y primaria; el acceso igualitario sin discriminación por género o nacionalidad, con especial enfásis a las personas y grupos en situación de vulnerabilidad; la alfabetización; y construir y adecuar instalaciones educativas de acuerdo con las necesidades de la población (Naciones Unidas, 2015, p. 19). Entre las metas, es fundamental destacar la 4.7. que señala:

De aquí a 2030, hay que asegurar que todos los alumnos adquieran los conocimientos teóricos y prácticos necesarios para promover el desarrollo sostenible, entre otras cosas mediante la educación para el desarrollo sostenible y los estilos de vida sostenibles, los derechos humanos, la igualdad de género, la promoción de una cultura de paz y no violencia, la ciudadanía mundial y la valoración de la diversidad cultural y la contribución de la cultura al desarrollo sostenible. (Naciones Unidas, 2015, p. 20)

En la vía de cumplir las metas de los ODS, la Unesco contribuye con un modelo educativo basado en tres grandes dimensiones de la EDS: i) el contenido del aprendizaje, es decir, en torno al desarrollo de procesos educativos sobre sostenibilidad y temas relevantes (cambio climático, pobreza y equidad de género); ii) la pedagogía, en la cual se concibe el aprendizaje de un modo interactivo centrado en los estudiantes; iii) la transformación social, que se relaciona con el desarrollo de habilidades en los estudiantes para transformarse a sí mismos y a la sociedad en la que viven (Unesco, 2019).

Estas tres dimensiones son interdependientes y, en el ámbito universitario, se deben vincular con la transversalidad y multidisciplinariedad de la sostenibilidad. Esto quiere decir que el contenido de los aprendizajes se incorpora a la flexibilidad curricular en tanto integración de áreas del conocimiento; el uso de las tecnologías de la información y la comunicación como herramientas para la apropiación y el empoderamiento social; la capacitación sobre el desarrollo sostenible para los docentes y el personal administrativo; y la incorporación de los ODS en la gestión administrativa de la universidad, de manera que se propicien procesos educativos y de investigación aplicada que permitan transformar el campus universitario en un laboratorio de la sostenibilidad.

A su vez, la EDS debe integrar en sus dimensiones una mirada amplia e interdependiente de los ODS en el marco de la educación como un derecho humano cuya garantía incide en el disfrute de los demás derechos. Por ello, necesariamente la EDS debe reconocer su rol en la formación de ciudadanas y ciudadanos críticos y propositivos, con consciencia de que el contexto cultural y ecológicamente diverso debe adecuarse a las formas y procesos tradicionales de las comunidades. En esta perspectiva es importante considerar las clínicas jurídicas como un espacio que no solo es propicio para hacer posible la meta de promover los conocimientos sobre el desarrollo sostenible en la población estudiantil universitaria, sino para alcanzar, a través del fortalecimiento de su trabajo, las trasformaciones necesarias para lograr una sociedad más justa. 
Para ello, las clínicas jurídicas, en especial las de interés público, se perfilan como espacios en los cuales se promueve el litigio estratégico o de interés público conforme con el cual la selección de casos, según Correa (2010), tiene como fin "generar y promover cambios sociales, así como a reforzar el proceso participativo y democrático empoderando y educando a las comunidades" (p. 191).

En consecuencia, el ODS 4, que busca asegurar una educación de calidad, y el ODS 16, que apunta a promover una sociedad más justa como entorno propicio para el desarrollo sostenible a través de un mayor acceso a la justicia, son objetivos que logran concreción en el trabajo de las clínicas jurídicas. Una mirada general sobre este trabajo es el propósito del siguiente apartado.

\section{LA AGENDA DE ALGUNAS CLÍNICAS JURÍDICAS EN EL MUNDO Y LOS ODS}

En este apartado se describen brevemente las acciones de las clínicas jurídicas en diferentes partes del mundo. No se trata de una revisión exhaustiva de su trabajo ni pretende hacer una lista detallada de todas las clínicas jurídicas existentes, es más bien una aproximación general que da cuenta de los temas y la relevancia de su labor en el campo de la sostenibilidad a través del litigio de estratégico y sus fines de formación para la justicia social. Esta última cuestión exige una revisión inicial ${ }^{4}$.

La justicia social como el principal valor que promueve la enseñanza jurídica clínica en diferentes partes del mundo es un concepto que puede entenderse por lo menos desde tres perspectivas, lo que a su vez explica la diversidad de asuntos y estrategias que emplean las clínicas para llevar a cabo tal propósito. Estas tres perspectivas son la justicia social como distribución, citando a Rawls, Nussbaum y Sen (2010); como reconocimiento, conforme con Collins, Fraser y Honneth; y como participación, según Young, Miller, Fraser y Honneth (citado en Murillo y Hernández, 2011, p. 12). La primera definición se refiere a la distribución de recursos materiales y culturales, así como de capacidades. La segunda se relaciona con la idea del reconocimiento y el respeto por cada una de las culturas con base en la existencia de relaciones justas en la sociedad. Finalmente, el tercer concepto asume la justicia social como la posibilidad de la participación de las personas en las decisiones que afectan sus vidas en la sociedad en la que viven (Murillo y Hernández, 2011).

4 Aunque la reflexión de la enseñanza clínica en el derecho se presenta en los años treinta del siglo XX, entre los años sesenta y setenta estas se expanden en países como Estados Unidos, Canadá, Australia, Gran Bretaña e India, así como en regiones del sureste de África (Romano, 2016). Desde sus orígenes, la justicia social ha sido parte de los propósitos de formación que orientan las distintas áreas de trabajo de las clínicas jurídicas (Romano, 2016; Abramovich, 1999). Se podría decir que dichos objetivos formativos se empiezan a consolidar globalmente en los noventa con el surgimiento de la Alianza Global para la Educación en la Justicia (GAJE), cuya agenda está dirigida al alcance de la justicia social por medio de un abordaje comprensivo de la educación legal clínica, sin que se limitara a hablar de programas clínicos en las facultades de derecho (Santow y Wachira, 2011). 
Como se verá más adelante, las clínicas jurídicas vinculan el trabajo por la justicia social a distintas áreas de la sostenibilidad, lo cual a su vez se enlaza las metas de los ODS. En estos escenarios, las clínicas asumen un importante rol como actores del desarrollo que, definitivamente, deben ser tenidas en cuenta dentro del enfoque multiactor de la Agenda 2030 como interlocutores de los Gobiernos (Departamento Nacional de Planeación, 2018, p. 47). Este enfoque promueve la interacción de los Gobiernos con todas las personas interesadas para establecer alianzas que permitan alcanzar las metas de los ODS5.

Por ejemplo, en los Estados Unidos, la Asociación para la Educación Legal Clínica (CLEA por sus siglas en inglés) ha establecido como uno de sus objetivos de su plan estratégico "alcanzar y promover la justicia y la diversidad como valores centrales de la profesión legal" (CLEA, 2016). Por un lado, dicha finalidad se enmarca en lo propuesto por el ODS 4 sobre la inclusión de la diversidad en la educación; por el otro, la educación clínica se convierte en un mecanismo para alcanzar la meta 16.3 del ODS de paz, justicia e instituciones sólidas, relacionado con la garantía del acceso a la justicia para todos en el marco de los Estados de derecho.

En una encuesta nacional realizada por el Centro para el Estudio de Educación Aplicada estadounidense entre los años 2016-17, se encontró que ciento ochenta y siete facultades de derecho encuestadas reportaron un total de 1,433 clínicas jurídicas que trabajan en diferentes temas. Todas las facultades, excepto cuatro, afirmaron tener por lo menos una clínica jurídica (Csale, 2017). Son treinta y ocho diferentes temas en los que se enfocan las clínicas jurídicas. Sin embargo, la mayoría de ellos tienen relación con las cuestiones abordadas por los ODS:

- El tema de los derechos de la niñez, trabajado por 39 \% de las clínicas jurídicas (Csale, 2017), está íntimamente relacionado con los ODS 1, 3 y 4, específicamente lo pertinente al cumplimiento de la meta 1.2 sobre la reducción a la mitad del número de niñas y niños en condición de pobreza, 3.2 sobre poner fin a muertes evitables de niñas y niños y 4.1 sobre el acceso a la educación de la niñez.

- El tema del medio ambiente, reportado por un $24 \%$ de las clínicas jurídicas (Csale, 2017), está conectado con los ODS 6 —agua limpia y saneamiento-; 7 —energía asequible y no contaminante-; 11 - ciudades y comunidades sostenibles-; y 13, 14 y 15 - acción por el clima, vida submarina y vida de ecosistemas terrestres respectivamente-.

\footnotetext{
"La Agenda 2030 para el Desarrollo Sostenible y sus ODS es el resultado de un proceso intergubernamental abierto e inclusivo y con activa participación de actores no gubernamentales estratégicos para su consecución. El texto de la Agenda 2030 reconoce la necesidad de adoptar un enfoque multiactor, que involucre a todos los actores del desarrollo, entendidos como Gobiernos, representantes de las otras ramas de poderes públicos, las instituciones internacionales, autoridades locales, representantes de diferentes etnias, organizaciones de la sociedad civil, el sector privado, los medios de comunicación, la comunidad científica y académica y la ciudadanía" (Cepal, 2018, p. 47).
} 
- El tema del desarrollo económico comunitario, trabajado por $23 \%$ de las clínicas (Csale, 2017), está relacionado con el ODS 11 sobre ciudades y comunidades sostenibles.

- El tema de los derechos humanos, trabajado en 21 \% de las clínicas jurídicas (Csale, 2017), es un eje transversal a todos los ODS.

- El tema del derecho a la salud y de las personas en situación de discapacidad (15\% y 12 \% respectivamente) (Csale, 2017) se relaciona con los ODS 3 — salud y bienestar-; 4 —educación de calidad — y 10 -reducción de desigualdades—.

Como ejemplo de este trabajo, es pertinente citar la labor de la clínica jurídica de la Universidad de Berkeley en el campo de los derechos humanos. Los temas objeto de intervención son la equidad de género, paz y justicia transicional, responsabilidad empresarial, cambio climático, acceso al agua, y reducción de la contaminación (Universidad de California, 2019). Por su parte, en la Universidad de Yale, existen alrededor de veinticinco clínicas jurídicas trabajando en diferentes áreas del derecho, entre las que se destacan: violencia de género (Clínica de Violencia de Género Beshar-Lehner), medio ambiente (Clínica de Protección Ambiental), derechos humanos (Clínica Internacional de Derechos Humanos de Lowestein) y desarrollo económico comunitario (Centro Ludwig para el Desarrollo Económico y Comunitario) (Facultad de Derecho de Yale, 2019).

En la Universidad de Harvard también existe un buen número de clínicas enfocadas en temas priorizados en los ODS. Estos temas son educación de calidad e inclusiva; ambiente y energía; y seguridad alimentaria (Universidad de Harvard, 2019) ${ }^{6}$. A estas temáticas se suma la Universidad de Chicago, cuyas clínicas trabajan en temas relacionados con la protección ambiental, pobreza y acceso a la vivienda (Universidad de Chicago, 2019). Asimismo, en la Universidad de Minnesota hay dos clínicas que se enfocan en temas ambientales y energía, así como en derechos humanos (Universidad de Minnesota, 2019).

También es importante resaltar que, en los Estados Unidos, las clínicas jurídicas apuestan por los desarrollos tecnológicos tendientes a facilitar acceso a la justicia de los usuarios. En la Facultad de Derecho de Chicago-Kent se han desarrollado varias iniciativas en conjunto con otras organizaciones que incluyen el desarrollo de un software en el que los usuarios pueden construir e implementar modelos de automatización de documentos que permitan, por un lado, generar nuevos contenidos automatizados en páginas web de asesorías legales y, por el otro, producir entrevistas guiadas y otros recursos técnicos que organizaciones legales pueden

6 Las clínicas que tramitan estas causas son: Clínica de Derecho Educativo/Inicitaiva de política de Trauma y Aprendizaje (TLPI), Clínica de Políticas y Derecho Ambiental de Emmett y Legislación y política alimentaria del Centro para la innovación en material de leyes y políticas de salud. 
usar para reducir las barreras de acceso a la justicia para las personas de más bajos recursos (Facultad de Derecho de Chicago-Kent, 2019).

Otra gran innovación tecnológica ha tomado lugar en el Centro Jurídico Georgetown en el que los estudiantes han desarrollado aplicaciones en páginas web que les ayudan a las personas a identificar y entender los problemas legales que enfrentan y evaluar sus opciones legales. Por su parte, la Ayuda Legal en Línea de Illinois (ILAO) ha creado un juego que ayuda a las personas a entender cuestiones relacionadas con desalojos (Universidad de Manchester, 2016, p. 14).

En el mundo anglosajón también es importante citar las clínicas universitarias en Canadá, país en el que desde 1970 se fortaleció la creación de clínicas enfocadas en temas de interés público (Giddings et al., 2013, p. 59) ${ }^{7}$. Existen muchos ejemplos del trabajo clínico en Canadá. Vale resaltar la Asociación Canadiense de Educación Clínica Legal ${ }^{8}$ que tiene en cuenta temas de género y, en general, sobre la defensa de los derechos humanos (Accle, 2019).

En otros continentes donde los programas de cooperación estadounidense influenciaron la creación de clínicas jurídicas, como es el caso en el Sur de África y el Sur de Asia, se encuentran también ejemplos importantes del papel de las clínicas universitarias en el campo de los ODS. En el primer caso, Sur de África, las acciones de las clínicas se han dirigido principalmente a ponerle fin a la pobreza, la reducción de las desigualdades y la ampliación del acceso a la justicia de comunidades en condición de vulnerabilidad. En el segundo caso, en el Sudeste Asiático, el común denominador ha sido el trabajo por una mejor educación legal y el desarrollo de programas de justicia comunitaria ${ }^{10}$.

7 En 1971, el Gobierno Federal financió la creación de cinco clínicas legales comunitarias: Servicio legal comunitario Inc. de Point St Charles en Montreal, Asistencia jurídica para estudiantes en Dalhousie, Escuela de Derecho Osgood Hall (Servicio legal Comunitario de Parkdale) y la Sociedad de asistencia jurídica de Saskatoon. Estas clínicas tenían una visión más amplia de la promoción del acceso a la justicia que los servicios legales convencionales de la época, por lo que establecieron una línea clara de trabajo: promover el cambio social (Winkler, 2019, p. 8).

8 De esta red hacen parte clínicas como Rise Women's Legal Centre Columbia y Clínica legal comunitaria de la Universidad de British Columbia y la Clínica de Interés Público de la Universidad de Calgary (Accle, 2019).

9 En el Sur de África, en países como Sudáfrica y Zimbabue desde los años setenta, Botsuana en los años ochenta, Suzilandia en los noventa, y en Lesoto, Namibia, Zambia y Mozambique y Malawi en la primera década del 2000 se implementan clínicas jurídicas que, con el precedente del trabajo por los derechos civiles en épocas del apartheid, concentran su actividad en la prestación de servicios gratuitos a personas en condición de pobreza (Mcquoid-Mason, Mukundi y Ojukwu, 2013, pp. 79-80).

10 En la Universidad de Filipinas se originó el movimiento clínico con influencia de las clínicas jurídicas estadounidenses, y luego se extendió a otros países como Camboya, Tailandia, Indonesia, Laos, Malasia, Vietnam y Singapur, en los que la cooperación internacional fue clave para su desarrollo (Lasky y Prasad, 2013, pp. 99-101). 
En el caso de Europa, la reflexión sobre la necesidad de la enseñanza práctica en las facultades de derecho se presentó hasta finales de los años noventa gracias al proceso de Bolonia y la creación del Espacio Europeo de Educación Superior (Blázquez, 2013) ${ }^{11}$. Desde el año 2012, se puede decir que se expandió la educación clínica en la Europa occidental y para el año 2016 habían alrededor de cien clínicas legales en varios países de la región (Alemanno y Khadar, 2018). Ello estuvo acompañado de la creación de la Red Europea para la Educación Clínica Legal (Encle) en 2012, que incrementó la visibilidad y aceptación de la enseñanza clínica en la región; en Reino Unido y Polonia la Educación Clínica es significativamente extendida (Alemanno y Khadar, 2018).

En el Reino Unido, por ejemplo, actualmente las clínicas se enfocan en el trabajo probono y la mayoría están organizadas a través de una red de clínicas jurídicas llamada Law Works Clinic Network. En marzo de 2018, esta red estaba conformada por doscientas veintinueve clínicas legales activas. Para este año, el $35 \%$ de las clínicas jurídicas se concentraban en el área de familia, en especial en la asesoría sobre violencia doméstica, trabajo que encaja en las metas del ODS 16 sobre la "reducción de todas las formas de violencia". Un 17 \% se dedica a asesorar en cuestiones de derecho laboral, trabajo que resalta su papel como actor clave en el cumplimiento del ODS 8 sobre "trabajo decente y crecimiento sostenible" (Naciones Unidas, 2020). Y un 15 \% atiende casos relacionados con el acceso a vivienda, cuyo enfoque en la pobreza guarda directa conexión con el ODS 1 sobre la "reducción de la pobreza" (Lawworks Clinics Network, 2018). Las clínicas jurídicas de la Universidad de Sussex (Universidad de Sussex, 2019), Bristol (Universidad de Bristol, 2019), Essex (Universidad de Essex, 2019) y SOAS son las clínicas más sobresalientes en el país con relación a su trabajo en diversos temas de derechos humanos.

Cabe señalar, como otro ejemplo en la región europea, el trabajo de la enseñanza clínica en España. En este país se creó una red que alberga alrededor diecinueve de clínicas jurídicas (Red Española de Clínicas Jurídicas, 2020). Debe citarse, por ejemplo, la Clínica Jurídica de la Universidad de Oviedo cuya actividad está centrada "en los objetivos de desarrollo sostenible desde una perspectiva jurídica" (Universidad de Oviedo, 2020)12. Aunque son muchos los ejemplos en este país, cabe resaltar las acciones relacionadas con la atención de población con VIH o sida que está en consonancia con el ODS 3, "salud y bienestar", a través de la meta de poner fin a la epidemia del sida (ONU SIDA, 2020). Tal es el caso de la clínica jurídica de la Universidad de Alcalá y de la Clínica Jurídica Loiola de la Facultad de Derecho en la Universidad de Deusto. Estas instituciones prestan acompañamiento a personas con VIH, lo que incluye

11 Con el apoyo de donantes estadounidenses y europeos se establecieron las primeras clínicas jurídicas en la región, concentradas principalmente en Europa central y oriental (Alemanno y Khadar, 2018).

12 En España, el primer antecedente de la instalación de una clínica jurídica se presentó en la Universidad de Rovira i Virigili en Tarragona, en el año de 2002, cuyo trabajo se concentró en derecho penitenciario; más tarde, en 2005, en esta misma universidad, se conformó la Clínica de Derecho Ambiental (Blázquez, 2013, p. 208). 
sesiones de apoyo, atención en casos ante la justicia y la elaboración de folletos en diferentes idiomas para informar sobre sus derechos (Ramiro y Ramírez, 2018).

Por su parte, en Latinoamérica ${ }^{13}$ existe una importante presencia de clínicas jurídicas universitarias, impulsadas en su momento por la Red Latinoamericana de Clínicas Jurídicas de Interés Público ${ }^{14}$. La agenda temática de las clínicas jurídicas en Latinoamérica gira en torno del interés público (Castro-Buitrago et al., 2013) y la exigibilidad de los derechos humanos. Entre las iniciativas que mueven a las clínicas jurídicas de la región está la protección de los derechos humanos, siempre teniendo como enfoque de fondo el trabajo por la consecución de un mejor acceso a la justicia de las minorías y de personas o grupos en condición de vulnerabilidad.

En un contexto más amplio como el iberoamericano, lo que incluye las clínicas de las universidades españolas, Londoño (2015, pp. 98-116) identifica los temas prioritarios de derechos humanos abordados en el trabajo clínico, todos ellos con una estrecha relación con la consecución de la metas de los ODS. En materia de derechos civiles resaltan los derechos políticos, el acceso a la información, la lucha contra la discriminación, la objeción de consciencia, la memoria, la justicia transicional y la atención a víctimas del conflicto. En lo relacionado con los derechos económicos, sociales y culturales, es relevante el trabajo en derecho a la salud y a la alimentación para los niños y las niñas, y el derecho a la vivienda. Por último, en lo que respecta a la defensa de los derechos colectivos se identifican el derecho a un ambiente sano, derechos de los consumidores y usuarios de servicios públicos. En el mismo sentido, se indican los grupos poblaciones que atienden las clínicas jurídicas iberoamericanas: mujeres, personas con discapacidad, migrantes, refugiados y desplazados, personas mayores, población Lgbti, pueblos indígenas, afroamericanos y comunidades tribales, víctimas de trata de personas y reclusos (Londoño, 2015, pp. 116-130).

En síntesis, con los ejemplos citados es posible aproximarse a señalar que, en gran parte del mundo, las clínicas jurídicas han venido adoptando un importante rol de promoción y acción en la defensa de los derechos humanos vinculados con los ODS, siempre conectando sus acciones con la transformación social a través del trabajo por una justicia de calidad. Así lo comprueba, incluso, Naciones Unidas al vincular el

13 En Latinoamérica, la enseñanza clínica de acuerdo con las investigaciones en la materia tuvo dos grandes influencias provenientes del modelo educativo clínico estadounidense. El movimiento por el derecho y el desarrollo en los años sesenta (Rodríguez, 2006) dieron lugar, en el contexto de las dictaduras latinoamericanas del momento, a estrategias de alto impacto desarrolladas originalmente por la Clínica de Derechos Humanos e Interés Público del Centro de Estudios Legales y Sociales (CELS) y la Universidad de Buenos Aires (1994); la Clínica de Derecho Penal de la Universidad de Comahue y la Clínica de Interés Público de la Universidad de Palermo (Londoño, 2016). Una segunda generación de este movimiento se dio en los años noventa, promovido por la Red Latinoamericana de Clínicas Jurídicas de Interés Público.

14 La Red Latinoamericana de Clínicas Jurídicas de Interés Público y el modelo de clínicas de interés público "tuvo mayor influencia en Chile, Argentina y Perú por medio del Programa Latinoamericano de Acciones de Interés Público y Derechos Humanos coordinado en su momento por la Universidad Diego Portales y financiado principalmente por la Fundación Ford (González, 2004, p. 8)" (Castro-Buitrago, 2015, p. 73). 
trabajo clínico con los ODS. En el año 2017, se creó el Fondo para los Objetivos de Desarrollo Sostenible enfocado en identificar retos, oportunidades y mejores prácticas relacionadas con el Objetivo 16. En el marco de este fondo, tuvo lugar un proyecto llevado a cabo por las universidades de Navarra y Pensilvania, en el que, a través del análisis de los resultados de las actividades clínicas, pudieron concluir que la falta de acceso a la justicia socava el logro de los ODS (SDFG, 2019).

En este punto es importante señalar que con la anterior síntesis no se quiere afirmar que todas las clínicas jurídicas estén de acuerdo con el concepto y modelo de desarrollo promovido por los ODS y la Agenda 2030. Puede incluso que existan posiciones en contra de la manera en que se plantean sus metas y se promueven en cada país. Alineadas o no al modelo de desarrollo impuesto, lo cierto es que las clínicas jurídicas centran su labor en los temas clave para alcanzar una sociedad más justa, lo que implica mayor bienestar para todas las personas. Su trabajo de mediación entre gobiernos y comunidades, desde diferentes ópticas locales que llegan a cuestionar la perspectiva hegemónica del desarrollo, merece un análisis más profundo que va más allá de este estudio.

\section{EL TRABAJO DE LAS CLIINICAS JURÍDICAS COLOMBIANAS Y LOS ODS}

Los temas que asumen las clínicas colombianas son en gran parte similares a los abordados por las demás clínicas en el mundo, por lo que podría decirse que, al igual que la Agenda 2030, la enseñanza clínica posee una agenda global cuyo principal eje es la educación para la justicia social (Bloch, 2013).

El movimiento clínico inicia en el país a finales de los años noventa del siglo pasado (Castro-Buitrago et al., 2013, p. 150) y logra una importante expansión a finales de la primera década del presente siglo con la creación de la Red Colombiana de Clínicas Jurídicas de Interés Público en 2009 (Londoño, 2015, p. 92). En su origen fue fundamental el impulso dado por la aprobación de la Ley 472 de 1998, que reguló las acciones populares y permitió el litigio de los estudiantes de derecho gracias a la introducción de la figura de la legitimación activa amplia (Castro-Buitrago, 2015, pp. 74-75). En consecuencia, los primeros asuntos de estudio y de ejercicio de defensa fueron los relacionados con los derechos colectivos, entre ellos el derecho a un ambiente sano y el equilibrio ecológico, la moralidad administrativa, la defensa de los bienes y el espacio público, salubridad y seguridad públicas (Londoño, 2009; Londoño, Castro y Olarte, 2002).

En la última década, aunque gran parte de los casos tramitados tienen que ver con la defensa de los derechos colectivos, estos asuntos son abordados desde la protección de los derechos de población específica, como es el caso de las personas en condición de discapacidad, población desplazada y víctimas del conflicto interno, personas mayores, mujeres, niñas y niños, población Lgtbi, habitantes de calle y migrantes. 
En este contexto, puede identificarse el fortalecimiento del estudio de casos clínicos en el marco del derecho de los derechos humanos con un enfoque diferencial (Oficina en Colombia del Alto Comisionado de la ONU para los DDHH, 2019). En especial, debe mencionarse la labor de las clínicas en la construcción de paz en el contexto del posacuerdo a partir del litigio estratégico para la defensa de los derechos de las víctimas como el derecho a la participación, la reparación administrativa, la restitución de tierras y el trabajo comunitario para la búsqueda de la paz (Castillo, 2018).

El estudio de los casos, los objetivos perseguidos y los éxitos alcanzados por las clínicas jurídicas del país dan cuenta del importante papel que han asumido como actores clave para la transformación social, pero, sobre todo, para alcanzar una educación de calidad (Molina-Saldarriaga et al., 2015). Con ello, han contribuido con la meta 4.7 del ODS 4 de asegurar el conocimiento teórico y práctico para la promoción del desarrollo sostenible en los temas de "derechos humanos, la igualdad de género, la promoción de una cultura de paz y no violencia, la ciudadanía mundial y la valoración de la diversidad cultural" (Cepal, 2018, p. 22). En este sentido, puede afirmarse que, en concreto, la enseñanza clínica en Colombia tributa al tercer eje de la EDS ${ }^{15}$ :

(3) Aumentar la comprensión y conciencia pública en relación con la sostenibilidad. Para alcanzar los objetivos del desarrollo sostenible es necesario contar con ciudadanos que estén informados acerca de la sostenibilidad y de las acciones diarias necesarias para alcanzar los objetivos de ésta a nivel comunitario y nacional. Es preciso educar a la comunidad en general y contar con medios de comunicación responsables que estén comprometidos con alentar a un pueblo, informado y activo, a aprender a lo largo de la vida. (Unesco, 2012, p. 35)

Para alcanzar los propósitos del tercer eje de la EDS, el trabajo clínico que han desarrollado las facultades de derecho en Colombia y en el mundo sin duda es un modelo inspirador. En la actualidad, treinta y una instituciones de educación superior promueven la educación jurídica clínica y se identifican treinta y seis clínicas jurídicas activas a 2020.

En la tabla 1 se indican las clínicas jurídicas de interés público existentes en el país, los temas de trabajo y las instituciones de educación superior a las que pertenecen.

15 Los otros ejes son i) mejorar el acceso y la retención en educación básica de calidad; ii) reorientar los programas educativos existentes para lograr la sostenibilidad; iii) proporcionar formación a todos los sectores de la fuerza laboral (Unesco, 2012, p. 35). 
Tabla 1. Clínicas jurídicas colombianas y temas de trabajo

\begin{tabular}{|c|c|c|c|}
\hline $\begin{array}{l}\text { Institución } \\
\text { de educación } \\
\text { superior }\end{array}$ & Clínicas & Temas de trabajo & Página web \\
\hline $\begin{array}{l}\text { U. del Rosario } \\
\text { (Bogotá) }\end{array}$ & $\begin{array}{l}\text { Grupo de Acciones Públicas } \\
\text { (GAP) } \\
\text { Clínica de Derecho Penal } \\
\text { Internacional y de Violencia } \\
\text { Intrafamiliar y Género } \\
\text { Clínica de ética y } \\
\text { transparencia }\end{array}$ & $\begin{array}{l}\text { Derechos humanos } \\
\text { Acceso a la justicia } \\
\text { Ambiente } \\
\text { Violencia } \\
\text { Intrafamiliar y } \\
\text { Género } \\
\text { Corrupción y su } \\
\text { impacto en el sector } \\
\text { público y privado }\end{array}$ & $\begin{array}{l}\text { https://www.urosario. } \\
\text { edu.co/consultorio- } \\
\text { juridico/Clinicas- } \\
\text { Juridicas/ }\end{array}$ \\
\hline $\begin{array}{l}\text { U.Sergio } \\
\text { Arboleda } \\
\text { (Bogotá) }\end{array}$ & $\begin{array}{l}\text { Clínica Jurídica de Interés } \\
\text { Público Oswaldo Abello } \\
\text { Noguera. }\end{array}$ & $\begin{array}{l}\text { Derechos humanos } \\
\text { Salud } \\
\text { Educación } \\
\text { Saneamiento }\end{array}$ & $\begin{array}{l}\text { http://www. } \\
\text { usergioarboleda.edu. } \\
\text { co/santamarta/assets/ } \\
\text { clinica-juridica-interes- } \\
\text { publico-17-08-2017.pdf }\end{array}$ \\
\hline $\begin{array}{l}\text { U. Javeriana } \\
\text { (Bogotá) }\end{array}$ & $\begin{array}{l}\text { Clínica Jurídica Derecho y } \\
\text { Territorio } \\
\text { Pertenece al Grupo de } \\
\text { Investigación en Justicia } \\
\text { Social, Teoría Jurídica } \\
\text { General y Teoría Política }\end{array}$ & $\begin{array}{l}\text { Derechos humanos } \\
\text { Agro y minería } \\
\text { Ambiente }\end{array}$ & $\begin{array}{l}\text { https://www.javeriana. } \\
\text { edu.co/investigacion/ } \\
\text { semillero-de- } \\
\text { investigacion-clinica- } \\
\text { juridica-en-derecho-y- } \\
\text { territorio }\end{array}$ \\
\hline $\begin{array}{l}\text { U. del Bosque } \\
\text { (Bogotá) }\end{array}$ & $\begin{array}{l}\text { Clínica Legal e } \\
\text { Interdisciplinar del Medio } \\
\text { Ambiente, Universidad El } \\
\text { Bosque (Clima) }\end{array}$ & Ambiente & \\
\hline $\begin{array}{l}\text { Universidad } \\
\text { de La Sabana } \\
\text { (Chía, } \\
\text { Cundinamarca) }\end{array}$ & $\begin{array}{l}\text { Clínica Jurídica de Interés } \\
\text { Público y Derechos } \\
\text { Humanos }\end{array}$ & Derechos Humanos & $\begin{array}{l}\text { https://www.unisabana. } \\
\text { edu.co/programas/ } \\
\text { carreras/facultad-de- } \\
\text { derecho-y-ciencias- } \\
\text { politicas/derecho/ } \\
\text { nuestros-recursos/ } \\
\text { consultorio-juridico/ }\end{array}$ \\
\hline $\begin{array}{l}\text { U. de Los Andes } \\
\text { (Bogotá) }\end{array}$ & $\begin{array}{l}\text { Clínica Jurídica de Medio } \\
\text { Ambiente y Salud Pública } \\
\text { (MASP) } \\
\text { Grupo de Prisiones (GDP) } \\
\text { Programa de Acción por } \\
\text { la Igualdad y la Inclusión } \\
\text { Social (Paiis) } \\
\text { Clínica Jurídica de Migrantes }\end{array}$ & $\begin{array}{l}\text { Salud pública } \\
\text { Ambiente y salud } \\
\text { ambiental } \\
\text { Derechos de las } \\
\text { personas mayores, } \\
\text { Lgtbi, migrantes } \\
\text { y personas con } \\
\text { discapacidad } \\
\end{array}$ & $\begin{array}{l}\text { https:// } \\
\text { consultoriojuridico. } \\
\text { uniandes.edu.co/ } \\
\text { Paginas/Home.aspx }\end{array}$ \\
\hline
\end{tabular}




\begin{tabular}{|c|c|c|c|}
\hline $\begin{array}{l}\text { Institución } \\
\text { de educación } \\
\text { superior }\end{array}$ & Clínicas & Temas de trabajo & Página web \\
\hline $\begin{array}{l}\text { U. de Medellín } \\
\text { (Medellín) }\end{array}$ & $\begin{array}{l}\text { Clínica Jurídica de Interés } \\
\text { Público }\end{array}$ & $\begin{array}{l}\text { Ambiente } \\
\text { Cambio climático } \\
\text { Migrantes } \\
\text { Derechos de las } \\
\text { mujeres } \\
\text { Responsabilidad } \\
\text { social empresarial } \\
\end{array}$ & $\begin{array}{l}\text { https://www.udem.edu. } \\
\text { co/index.php/clinica- } \\
\text { juridica-de-interes- } \\
\text { publico/clinica-juridica- } \\
\text { informacion-general }\end{array}$ \\
\hline $\begin{array}{l}\text { U. Autónoma } \\
\text { Latinoaméricana } \\
\text { (Unaula) } \\
\text { (Medellín) }\end{array}$ & $\begin{array}{l}\text { Clínica Jurídica de Interés } \\
\text { Público } \\
\text { Clínica Decreto } 1500 \text { de } \\
2018\end{array}$ & $\begin{array}{l}\text { Ambiente } \\
\text { Migrantes } \\
\text { Gestión del riesgo } \\
\text { Género } \\
\text { Derechos y } \\
\text { protección } \\
\text { de territorios } \\
\text { ancestrales de } \\
\text { las comunidades } \\
\text { indígenas }\end{array}$ & $\begin{array}{l}\text { https://www.unaula.edu. } \\
\text { co/clinica }\end{array}$ \\
\hline $\begin{array}{l}\text { U. Católica Luís } \\
\text { Amigó } \\
\text { (Medellín) }\end{array}$ & $\begin{array}{l}\text { Clínicas jurídicas de casos } \\
\text { concretos (Decreto } 1500 \\
\text { de } 2018 \text { y derechos a la } \\
\text { igualdad del pueblo raizal) }\end{array}$ & $\begin{array}{l}\text { Derechos y } \\
\text { protección } \\
\text { de territorios } \\
\text { ancestrales de } \\
\text { las comunidades } \\
\text { indígenas } \\
\text { Exigibildad de } \\
\text { derechos del pueblo } \\
\text { raizal }\end{array}$ & \\
\hline $\begin{array}{l}\text { Corporación } \\
\text { Universitaria } \\
\text { Americana } \\
\text { (Medellín) }\end{array}$ & $\begin{array}{l}\text { Clínica Jurídica de Interés } \\
\text { Público y Epístemología } \\
\text { Crítica }\end{array}$ & $\begin{array}{l}\text { Derechos humanos } \\
\text { y empresa } \\
\text { Paz }\end{array}$ & $\begin{array}{l}\text { https://americana.edu. } \\
\text { co/medellin/servicios/ } \\
\text { clinica-juridica/ }\end{array}$ \\
\hline $\begin{array}{l}\text { Unisabaneta } \\
\text { (Sabaneta, } \\
\text { Antioquia) }\end{array}$ & $\begin{array}{l}\text { Clínica Jurídica de la } \\
\text { Universidad de Sabaneta }\end{array}$ & $\begin{array}{l}\text { Derechos humanos } \\
\text { Derecho laboral } \\
\text { Género } \\
\text { Educación-niñez }\end{array}$ & $\begin{array}{l}\text { http://www.unisabaneta. } \\
\text { edu.co/archivo/ } \\
\text { estudiantes-de-clinica- } \\
\text { juridica-de-unisabaneta- } \\
\text { fomentan-la- } \\
\text { interaccion-universidad- } \\
\text { sociedad/ }\end{array}$ \\
\hline $\begin{array}{l}\text { U.Católica del } \\
\text { Oriente } \\
\text { (Rionegro, } \\
\text { Antioquia) }\end{array}$ & $\begin{array}{l}\text { Clínica Jurídica de Derechos } \\
\text { Humanos }\end{array}$ & $\begin{array}{l}\text { Derecho } \\
\text { penitenciario } \\
\text { Derechos de las } \\
\text { mujeres }\end{array}$ & $\begin{array}{l}\text { http://www.uco. } \\
\text { edu.co/extension/ } \\
\text { consultoriojuridico/ } \\
\text { Paginas/Clinica-Juridica. } \\
\text { aspx }\end{array}$ \\
\hline
\end{tabular}




\begin{tabular}{|c|c|c|c|}
\hline $\begin{array}{l}\text { Institución } \\
\text { de educación } \\
\text { superior }\end{array}$ & Clínicas & Temas de trabajo & Página web \\
\hline $\begin{array}{l}\text { U. ICESI } \\
\text { (Cali) }\end{array}$ & $\begin{array}{l}\text { Grupo de Acciones Públicas } \\
\text { de la Universidad Icesi } \\
\text {-GAPI- }\end{array}$ & $\begin{array}{l}\text { Salud pública } \\
\text { Desplazamiento } \\
\text { forzado } \\
\text { Derechos de la } \\
\text { ninez } \\
\text { Ambiente } \\
\text { Inclusión social } \\
\text { de personas con } \\
\text { discapacidad }\end{array}$ & $\begin{array}{l}\text { http://www.icesi.edu.co/ } \\
\text { centros-academicos/ } \\
\text { gapi/\#tab-517 }\end{array}$ \\
\hline $\begin{array}{l}\text { Pontificia } \\
\text { Universidad } \\
\text { Javeriana de } \\
\text { (Cali) }\end{array}$ & $\begin{array}{l}\text { Clínica Jurídica de Derechos } \\
\text { Humanos }\end{array}$ & $\begin{array}{l}\text { Derechos humanos } \\
\text { Ambiente }\end{array}$ & \\
\hline $\begin{array}{l}\text { U. Santiago de } \\
\text { Cali } \\
\text { (Cali) }\end{array}$ & $\begin{array}{l}\text { Clínica Jurídica en Derechos } \\
\text { Humanos }\end{array}$ & $\begin{array}{l}\text { Vinculación laboral } \\
\text { Acoso escolar } \\
\text { Discriminación } \\
\text { Género } \\
\text { Derecho de las } \\
\text { mujeres }\end{array}$ & $\begin{array}{l}\text { https://derecho.usc.edu. } \\
\text { co/index.php/clinica- } \\
\text { juridica/presentacion- } \\
\text { clinica-juridica }\end{array}$ \\
\hline $\begin{array}{l}\text { U. San } \\
\text { Buenaventura } \\
\text { de Cali (Cali) }\end{array}$ & $\begin{array}{l}\text { Clínica Jurídica de Interés } \\
\text { Público }\end{array}$ & $\begin{array}{l}\text { Derechos humanos } \\
\text { Derechos de las } \\
\text { mujeres }\end{array}$ & $\begin{array}{l}\text { https://www.usbcali.edu. } \\
\text { co/node/1475 }\end{array}$ \\
\hline $\begin{array}{l}\text { U. Autónoma de } \\
\text { Bucaramanga, } \\
\text { UNAB } \\
\text { (Bucaramanga) }\end{array}$ & $\begin{array}{l}\text { Clínica Jurídica de Interés } \\
\text { Púbico y Derechos } \\
\text { Humanos }\end{array}$ & $\begin{array}{l}\text { Personas con } \\
\text { discapacidad } \\
\text { Habitantes de calle } \\
\text { Trata de personas } \\
\text { Interrupción del } \\
\text { embarazo }\end{array}$ & $\begin{array}{l}\text { https://www.unab. } \\
\text { edu.co/publicaciones/ } \\
\text { cl\%C3\%ADnica- } \\
\text { jur\%C3\%ADdica- } \\
\text { m\%C3\%A1s-all\%C3\%A1- } \\
\text { los-c\%C3\%B3digos }\end{array}$ \\
\hline $\begin{array}{l}\text { U. } \\
\text { Cooperativa de } \\
\text { Bucaramanga } \\
\text { (Bucaramanga) }\end{array}$ & Clínica Jurídica & $\begin{array}{l}\text { Niñez } \\
\text { Salud } \\
\text { Ambiente }\end{array}$ & \\
\hline $\begin{array}{l}\text { Fundación } \\
\text { Universitaria } \\
\text { Unisangil (San } \\
\text { Gil, Santander) }\end{array}$ & Clínica Jurídica & $\begin{array}{l}\text { Personas con } \\
\text { discapacidad } \\
\text { Ambiente } \\
\text { Niñez } \\
\text { Personas mayores } \\
\text { Comunidades } \\
\text { étnicas } \\
\text { Seguridad social }\end{array}$ & $\begin{array}{l}\text { https://www.unisangil. } \\
\text { edu.co/index. } \\
\text { php?option=com_co } \\
\text { ntentEview=articleEid } \\
=1815: \text { :clinica-juridica- } \\
\text { de-unisangil-estuvo-en- } \\
\text { encuentro-internacional } \\
\text { Ecatid=10:noticiasEIte } \\
\text { mid=564 }\end{array}$ \\
\hline
\end{tabular}




\begin{tabular}{|c|c|c|c|}
\hline $\begin{array}{l}\text { Institución } \\
\text { de educación } \\
\text { superior }\end{array}$ & Clínicas & Temas de trabajo & Página web \\
\hline $\begin{array}{l}\text { U.Sergio } \\
\text { Arboleda } \\
\text { (Santa Marta) }\end{array}$ & $\begin{array}{l}\text { Clínica Jurídica de Interés } \\
\text { Público }\end{array}$ & $\begin{array}{l}\text { Personas con } \\
\text { discapacidad } \\
\text { Servicios públicos }\end{array}$ & \\
\hline $\begin{array}{l}\text { U. de } \\
\text { Magdalena } \\
\text { (Santa Marta) }\end{array}$ & $\begin{array}{l}\text { Clínica Jurídica de derechos } \\
\text { humanos }\end{array}$ & $\begin{array}{l}\text { Educación } \\
\text { Niñez } \\
\text { Personas con } \\
\text { discapacidad }\end{array}$ & \\
\hline $\begin{array}{l}\text { U.del Norte } \\
\text { (Barranquilla) }\end{array}$ & $\begin{array}{l}\text { Grupo de Litigio e Interés } \\
\text { Público }\end{array}$ & $\begin{array}{l}\text { Salud } \\
\text { Ambiente } \\
\text { Espacio público }\end{array}$ & $\begin{array}{l}\text { https://www.uninorte. } \\
\text { edu.co/web/servicios-a- } \\
\text { la-comunidad/grupo-de- } \\
\text { litigio-e-interes-publico }\end{array}$ \\
\hline $\begin{array}{l}\text { Corporación } \\
\text { Universitaria } \\
\text { Autónoma del } \\
\text { Caribe. } \\
\text { (Barranquilla) }\end{array}$ & $\begin{array}{l}\text { Centro de Altos Estudios } \\
\text { para la Paz y Clínica Jurídica }\end{array}$ & $\begin{array}{l}\text { Derechos humanos } \\
\text { Justicia transicional }\end{array}$ & $\begin{array}{l}\text { http://clinicajuridica.uac. } \\
\text { edu.co/ }\end{array}$ \\
\hline $\begin{array}{l}\text { U. de Nariño } \\
\text { (Pasto) }\end{array}$ & $\begin{array}{l}\text { Clínica de Género y } \\
\text { Violencia Intrafamiliar }\end{array}$ & $\begin{array}{l}\text { Igualdad de } \\
\text { género Violencia } \\
\text { intrafamiliar } \\
\text { Derechos de las } \\
\text { comunidades Lgbti }\end{array}$ & \\
\hline $\begin{array}{l}\text { U. Libre de } \\
\text { Pereira } \\
\text { (Pereira) }\end{array}$ & $\begin{array}{l}\text { Clínica Jurídica de Interés } \\
\text { Público }\end{array}$ & Derechos humanos & \\
\hline $\begin{array}{l}\text { U. de Caldas } \\
\text { (Manizales) }\end{array}$ & Clínica Socio-Jurídica & $\begin{array}{l}\text { Derechos humanos } \\
\text { Ambiente } \\
\text { Migración } \\
\text { Gestión del riesgo } \\
\text { Conflicto } \\
\text { Derechos de los } \\
\text { pueblos indígenas }\end{array}$ & $\begin{array}{l}\text { https://www.ucaldas. } \\
\text { edu.co/portal/clinica- } \\
\text { sociojuridica-u-de- } \\
\text { caldas-atendera-casos- } \\
\text { de-impacto-social/ }\end{array}$ \\
\hline $\begin{array}{l}\text { U. de Manizales } \\
\text { (Manizales) }\end{array}$ & Clínica Jurídica & Inclusión & $\begin{array}{l}\text { https:// } \\
\text { observatorioumanizales. } \\
\text { wordpress.com/ } \\
\text { consultorio-juridico/ } \\
\text { clinica-juridica/ }\end{array}$ \\
\hline $\begin{array}{l}\text { U. } \\
\text { Surcolombiana } \\
\text { (Neiva) }\end{array}$ & $\begin{array}{l}\text { Clínica Jurídica de Interés } \\
\text { Público }\end{array}$ & $\begin{array}{l}\text { Derecho laboral } \\
\text { Defensa del } \\
\text { territorio y pos/ } \\
\text { acuerdo } \\
\text { Igualdad de género }\end{array}$ & \\
\hline
\end{tabular}




\begin{tabular}{|c|c|c|c|}
\hline $\begin{array}{l}\text { Institución } \\
\text { de educación } \\
\text { superior }\end{array}$ & Clínicas & Temas de trabajo & Página web \\
\hline $\begin{array}{l}\text { Fundación } \\
\text { Universitaria } \\
\text { Navarra (Neiva) }\end{array}$ & Clínica Jurídica & $\begin{array}{l}\text { Víctimas del } \\
\text { conflicto } \\
\text { Igualdad de género } \\
\text { Memoria } \\
\text { Ambiente }\end{array}$ & \\
\hline $\begin{array}{l}\text { Corporación } \\
\text { Universitaria de } \\
\text { del Meta (Neiva) }\end{array}$ & Clínica Jurídica & $\begin{array}{l}\text { Desplazamiento } \\
\text { interno } \\
\text { Víctimas del } \\
\text { conflicto }\end{array}$ & \\
\hline $\begin{array}{l}\text { U. de Ibagué } \\
\text { (Ibagué) }\end{array}$ & $\begin{array}{l}\text { Clínica Jurídica de Derechos } \\
\text { Humanos e Interés Público }\end{array}$ & $\begin{array}{l}\text { Personas mayores } \\
\text { Pueblos indígenas } \\
\text { Ambiente }\end{array}$ & $\begin{array}{l}\text { https://clinicajuridica. } \\
\text { unibague.edu.co/la- } \\
\text { clinica/quienes-somos }\end{array}$ \\
\hline
\end{tabular}

Fuente: elaboración propia.

Como se aprecia en la tabla 1, los temas de trabajo de las clínicas jurídicas colombianas tienen conexión con los asuntos y derechos que involucran los ODS. Para una mejor ilustración, la figura 2 presenta la relación entre los asuntos que tramitan las clínicas y los ODS a los cuales tributan.

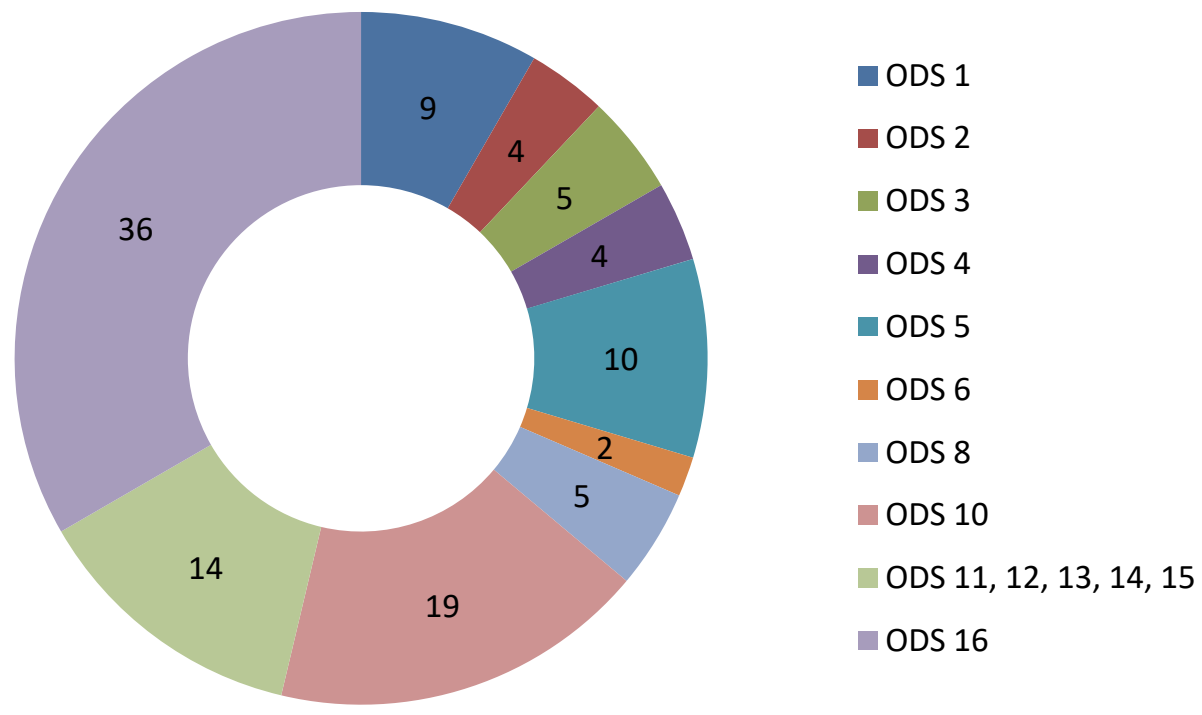

Figura 2. ODS y clínicas jurídicas colombianas

Fuente: elaboración propia. 
Todas las clínicas abordan sus casos bajo el enfoque de los derechos humanos y la promoción de la justicia social, con lo cual su trabajo puede relacionarse, de manera general con el marco de las metas del ODS 16 (Naciones Unidas, 2020), sea porque se alinean al modelo propuesto o para cuestionarlo al exigir una justicia eficaz en conexión con los reclamos de los usuarios atendidos. A partir de allí, no es fácil relacionar el trabajo de las clínicas jurídicas de manera exclusiva con un ODS. Los temas y asuntos particulares objeto de litigio estratégico son tramitados con miras a alcanzar diversos tipos de garantías de derechos que, con sus resultados, a su vez avanzan en la obtención de algunas metas correspondientes a distintos ODS.

En este sentido, por ejemplo, las clínicas jurídicas que centran su labor en los temas ambientales tramitan causas que no solo tienen que ver con la acción por el clima, la protección de los ecosistemas terrestres y la vida submarina, sino que vinculan, entre otros asuntos, las cuestiones sobre la educación de calidad, la reducción de la pobreza y de las desigualdades (Cepal, 2020a). Lo mismo podría decirse de las clínicas jurídicas que defienden los derechos de las personas con discapacidad, cuyos casos necesariamente se refieren a la reducción de la pobreza y desigualdades, el trabajo decente y la necesidad de ciudades y comunidades inclusivas (Cepal, 2020b). Lo anterior confirma que no es posible desarrollar estrategias en el marco de los ODS sin una perspectiva de integralidad.

Aun teniendo presente la variedad de asuntos tramitados y la interdependencia de los ODS que pueden estar involucrados con el trabajo de las clínicas colombianas, la figura 2 aproxima una representación de los temas objeto de su acción y los ODS con mayor vinculación. Como se aprecia, teniendo como fundamento los propósitos de mayor y mejor acceso a la justicia (ODS 16), las clínicas jurídicas han dirigido su atención en mayor medida a casos que se relacionan con la desigualdad social (ODS 10), los conflictos que afectan la protección ambiental y los problemas de igualdad de género (ODS 5).

Este importante trabajo que han llevado a cabo las clínicas jurídicas de interés público y derechos humanos por veinte años en el país requiere su reconocimiento como actor clave a ser tenido en cuenta en la toma de decisiones que involucran el fortalecimiento de la EDS en Colombia. En la revisión de literatura que sustenta este trabajo, sin embargo, no se encontró evidencia de documentos que relacionaran la enseñanza clínica del país con la EDS o con estrategias para alcanzar las metas internas para alcanzar los ODS, tal y como se formuló en el documento Conpes 3918 (Departamento Nacional de Planeación, 2018).

Este hallazgo permite sostener que la enseñanza clínica no ha alcanzado su reconocimiento como un ejemplo de educación jurídica clave para ser promovido por las políticas de educación nacionales y regionales, así como por las políticas vinculadas al logro de las metas de los ODS. En este escenario, se devela la deuda que el Ministerio de 
Educación Nacional y demás entidades encargadas tienen de alcanzar las metas de los ODS en el país con la promoción y fortalecimiento del trabajo de las clínicas jurídicas. Esta evidencia, a su vez, plantea el desafío para las clínicas jurídicas de ser reconocidas en su rol de mediadoras de la justicia social en el país y de actor relevante en la discusión sobre la obtención de las metas de los ODS.

\section{CONCLUSIONES}

La enseñanza clínica, ya sea en las ciencias médicas o en el campo del derecho, resalta la necesidad de una educación dirigida a la resolución de problemas reales que permita un entorno de aprendizaje significativo. En especial, el trabajo de las clínicas jurídicas en el mundo y concretamente en Iberoamérica posee un valioso papel en el diálogo para alcanzar las metas trazadas en la Agenda 2030 y los ODS. Como se advirtió desde un principio, la diversidad de temáticas en las que las clínicas desarrollan su trabajo no solo permite relacionarlas con los ODS 4 y 16 - en tanto su rol en la promoción de una educación jurídica de calidad y proveedores de servicios de asistencia jurídica para alcanzar mejores indicadores de acceso a la justicia de la población menos favorecida-, sino que es posible ubicarlas como agentes clave que desarrollan buenas prácticas para la implementación de varios ODS, como igualdad de género, reducción de las desigualdades, ciudades y comunidades sostenibles, producción y consumo resposable, trabajo decente, acción por el clima, vida de ecosistemas terrestres, entre otros.

La relación dialógica entre la EDS y la enseñanza clínica permite a su vez fortalecer los procesos pedagógicos en la medida que promueve la inclusión del enfoque de la sostenibilidad, la articulación y trabajo colaborativo entre disciplinas y favorece, por lo tanto, la implementación de estrategias innovadoras y de calidad para la formación de ciudadanas y ciudadanos comprometidos con la transformación social desde los pilares de justicia, equidad e inclusión. Estos aspectos son esenciales en el contexto colombiano marcado por la discriminación, la violencia y la inequidad, en el cual los espacios educativos como los que promueve la enseñanza clínica contribuyen con alternativas de solución a problemas estructurales por medio del estudio integral y relacional de los conflictos sociales.

En este orden de ideas, el trabajo de las clínicas jurídicas en el país requiere de un mayor reconocimiento en el marco de la consecución de los propósitos de la EDS. Estos aportes coinciden con los objetivos de la Agenda 2030 y los ODS, máxime si se tiene presente que esta forma de enseñar tiene fundamento en la justicia social como fin que guía todas las prácticas educativas. Ese reconocimiento y promoción permitiría desarrollar criterios específicos que contribuyan a valorar el cumplimiento de la meta 4.7 del ODS 4. 


\section{REFERENCIAS}

Abramovich, V. (1999). La enseñanza del derecho en las clínicas legales de interés público. Materiales para una agenda temática. Cuaderno de Análisis Jurídico. Serie de Publicaciones Especiales, 9, 61-94. https://www.palermo.edu/derecho/pdf/Bibliografia-clinicas-juridicas/la_ensenanza_del_derecho_ en_las_clinicas_legales_de_interes_publico(2).pdf

Accle. (2019). Association for Canadian Clinical Legal Education. http://accle.ca/links/

Aguirre, C. (2010). La educacion clínica ayer y hoy. Revista Clínica Española (1), 45-48. https://doi. org/10.1016/j.rce.2009.04.002

Alba, D. (2017). Hacia una fundamentación de la sostenibilidad en la educación superior. Iberoamericana de educación, 15-34.

Alemanno, A. y Khadar, L. (Eds.). (2018). Reinventing Legal Education: How Clinical Education Is Reforming the Teaching and Practice of Law in Europe. Cambridge University Press, 1-26. https:// doi.org/10.1017/9781316678589

Blázquez, D. (2013). El Proceso de Bolonia y el Futuro de la Educación Jurídica Clínica en Europa: una visión desde España. En Bloch, F. (ed.). El movimiento global de clínicas jurídicas. Formando juristas en la justicia social. Tirant lo Blanch 201-216.

Bloch, F. (1982). The Andragogical Basis of Clinical Legal Education. Vand. L. Rev, 321-353.

Bloch, F. (2013). Introducción. En Bloch, F. (ed.). El movimiento global de clínicas jurídicas. Formando juristas en la Justicia Social. Tirant lo Blanch, 43-50.

Castillo, E. (2018). Encuentro Nacional de Clínicas Jurídicas de Interés Público. Ediciones Unibagué.

Castro-Buitrago, E. (2015). Un modelo de estrategia didáctica para la enseñanza clínica del derecho con énfasis en investigación. Indisciplinas, 1(1), 69-97.

Castro-Buitrago, E., Espejo, N., Puga, M. y Villareal, M. (2013). La Educación Jurídica Clínica en América Latina: hacia el Interés Público. En F. Bloch (ed.), El movimiento global de clínicas jurídicas. Formando juristas en la Justicia Social (pp. 137-158). Tirant lo Blanch.

Cepal (2018). Agenda 2030 y los Objetivos de Desarrollo Sostenible una oportunidad para America Latina y el Caribe. Naciones Unidas.

Cepal (2020a, 20 de septiembre). Indicadores ambientales ODS. Listado de indicadores relevantes para el monitoreo del pilar Objetivos de Desarrollo Sostenible (ODS). https://www.cepal.org/sites/default/files/events/files/ indicadores_ambientales_ods._listado_de_indicadores_relevantes_para_el_monitoreo_del_pilar_ ambiental_ède_los_ods.pdf

Cepal (2020b, 20 de septiembre). Indicadores de los ODS relacionados con la discapacidad para el seguimiento global. https://unstats.un.org/unsd/demographic-social/meetings/2017/chile--disability-meeting/ Session\%202/ECLAC.pdf

Chicago-Kent College of Law. (2019, 25 de octubre). Legal Clinics. https://www.kentlaw.iit.edu/academics/ jd-program/practical-skills-training/legal-clinics

CLEA (2016, 9 de julio). Clea Strategic Plan. https://www.cleaweb.org/resources/Pictures/CLEA\%20 Strategic\%20Plan.Final.pdf

Correa, L. (2010). Litigio de alto impacto por medio de una clínica jurídica. En P. Cataño y J. Vásquez (ed.), La enseñanza clínica del derecho (pp. 187-233). Fundación Universitaria Luis Amigó. 
Departamento Nacional de Planeación. (2018). Documento Conpes 3918. Estrategia para la implementación de los objetivos de desarrollo sostenible (ODS) en Colombia.

Csale (2017). The 2016-17 Survey of Applied Legal Education. En University of Michigan (ed.), Center for the Study of Applied Legal Education. University of Michigan.

Fondo Internacional de Desarrollo Agrícola (2020, 6 de junio ). FIDA. https://www.ifad.org/es/ifadand-the-sdgs

Foucault, M. (1989). El nacimiento de la clínica. Siglo XXI Editores.

Frank, J. (1933). Why not a clinical lawyer school? U.Pa.L.Rev., 907.

Giddings, J., Klein, C., Burridge, R. y Gavigan, S. (2013). La Primera Ola de Educación Jurídica Clínica Moderna. Estados Unidos, Gran Bretaña, Canadá y Australia. En F. Bloch (ed.), El movimiento global de clínicas jurídicas. Formando juristas en la Justicia Social (pp. 55-78). Tirant lo Blanch.

González, F. (2004). El trabajo clínico en materia de derechos humanos e interés público en América Latina. Publicaciones de la Universidad de Deusto.

Lasky, B. y Prasad, M. (2013). El Movimiento Clínico en el Sudeste de Asia e India. Una Perspectiva comparada y Lecciones para ser aprendidas. En Bloch, F. (ed.), El movimiento global de clínicas jurídicas. Formando juristas en la Justicia Social (pp. 97-116). Tirant lo Blanch.

Lawworks Clinics Network. (2018, 1 de diciembre). Lawworks clinics Network report april 2017 - march 2018. https://www.lawworks.org.uk/sites/default/files/files/LW-Clinics-Report-2017-18-web.pdf

Londoño, B. (2009). Educación legal clínica y defensa de los derechos humanos. Casos paradigmáticos del Grupo de Acciones Públicas -GAP-. Editorial Universidad del Rosario.

Londoño, B. (2015). Educación legal clínica y litigio estratégico en Iberoamérica. Editorial Universidad del Rosario.

Londoño, B. (2016). Los cambios que requieren las clínicas jurídicas iberoamericanas. Estudio de caso en seis países de la región. Boletín Mexicano de Derecho Comparado, 49(146), 119-148.

Londoño, B., Castro, E. y Olarte, C. (2002). La defensa de lo público en la Universidad. Borradores de investigación. Editorial Universidad del Rosario.

Mcquoid-Mason, D., Mukundi, G. y Ojukwu, E. (2013). La Educación Jurídica Clínica en África. Formación jurídica y trabajo comunitario. En F. Bloch (ed.). El movimiento global de clínicas jurídicas. Formando juristas en la Justicia Socia (pp. 79-96)l. Tirant lo Blanch.

Mesa, M. (2000). La educación para el desarrollo. Centro de Investigación para la Paz.

Mesa, M. (2019). La educación para la ciudadanía global: una apuesta. Internacional de educación para la justicia social, 15-26.

Molina-Saldarriaga, C., Castro-Buitrago, E., Estrada-Jaramillo, L. y Pulgarín-Aguilar, C. (2015). De las tensiones entre la formación profesional y el impacto social. Una aproximación experiencial a los problemas que enfrentan las clínicas jurídicas. En M. Torres, P. Iregui, y S. Senior, El interés público en América Latina: reflexiones desde la educación legal clínica y el trabajo probono (pp. 336-354). Editorial Universidad del Rosario.

Murillo, F. y Hernández, C. (2011). Hacia un concepto de Justicia Social. Reice. Revista Iberoamericana sobre Calidad, Eficacia y Cambio en Educación, 9(4), 7-23. 
Naciones Unidas (2015). Transformar nuestro mundo: la Agenda 2030 para el desarrollo sostenible. Asamblea General.

Naciones Unidas (2020, 20 de agosto). Objetivos de Desarrollo Sostenible. https://www.un.org/ sustainabledevelopment/es/objetivos-de-desarrollo-sostenible/

Oficina en Colombia del Alto Comisionado de la ONU para los DDHH (2019, 2 de noviembre). Enfoque diferencial. https://www.hchr.org.co/index.php/76-boletin/recursos/2470-ique-es-el-enfoquediferencial

ONU SIDA (2020, 18 de agosto). El sida y los objetivos de desarrollo sostenible. https://www.unaids.org/es/ AIDS_SDGS

Ramiro, M. y Ramírez, P. (2018). El acceso a la justicia por personas con VIH: la experiencia de la Clínica Legal de la Universidad de Alcalá como aprendizaje-servicio. Oñati Socio-Legal Studies, 4, 464-487.

Red Española de Clínicas Jurídicas (2020, 18 de agosto). Quiénes somos. http://clinicas-juridicas.blogspot. $\mathrm{com} / \mathrm{p} /$ quienes-somos.html

Romano, M. (2016). The history of legal clinics in the us, europe and around the world. Diritto $E$ Questioni Pubbliche. Rivista di Filosofia del Diritto Cultura Giuridica, 16(1), 27-40.

Rodríguez, C. (2006). Globalización, reforma judicial y Estado de derecho en Colombia y América Latina: el regreso de los programas de derecho y desarrollo. Iusta, 179-216.

Santow, E. y Wachira, M . (2010). The Global Alliance for Justice Education. En F. Bloch, (ed.), The Global Clinical Movement: Educating Lawyers for Social Justice (pp. 371-382). Universidad de Oxford.

SDFG (2019, 28 de octubre). Traer acceso a la justicia en el centro de la Agenda 2030. https://www.sdgfund. org/bringing-access-justice-core-2030-agenda

Unesco (2012). Educación para el Desarrollo Sostenible. Lbro de consulta. Organización de las Naciones Unidas para la Educación, la Ciencia y la Cultura.

Unesco (2019, 14 de noviembre). ¿Qué es la Educación para el Desarrollo Sostenible? https://es.unesco. org/themes/educacion-desarrollo-sostenible/comprender-EDS

Universidad de Oviedo. (2020, 20 de Agosto). Noticias Clínica Jurídica de la Universidad de Oviedo. https://derecho.uniovi.es/noticias/-/asset_publisher/D9cF/content/llamamiento-clinica-juridica ?redirect $=\% 2$ Fnoticias\&fbclid $=$ IwAR2K3KSR-rFpRyHgmxHRhrHLcwBYNUmcbUXMzEWO7VpIz bm1_NITDMjvwdk

Universidad de Bristol. (2019, 25 de octubre). Human Rights Law Clinic. http://www.bristol.ac.uk/law/ careers-and-employability/human-rights-law-clinic/

Universidad de California. (2019, 25 de octubre). International Human Rights Law Clinic. https://www.law. berkeley.edu/experiential/clinics/international-human-rights-law-clinic/projects-and-cases/

Universidad de Chicago. (2019, 25 de octubre). Clinics. https://www.law.uchicago.edu/clinics

Universidad de Essex. (2019, 25 de octubre). Human Rights Centre Clinic. https://www.essex.ac.uk/centresand-institutes/human-rights/human-rights-centre-clinic

Universidad de Harvard. (2019, 25 de octubre). Clinical and Probono Programs. https://hls.harvard.edu/ content/uploads/2018/09/In-House-Clinics-Skills-Matrix_18-19.pdf 
Universidad de Manchester. (2019, 27 de octubre). Clinical legal education and experiential learning: Looking to the future. http://hummedia.manchester.ac.uk/schools/law/main/news/Clinical-Legal-EducationFinal-Report28.09.2016.pdf

Universidad de Minnesota. (2019, 25 de octubre). Environmental Law Clinic. https://www.law.umn.edu/ course/7012/environmental-and-energy-law-clinic

Universidad de Sussex . (2019, 25 de octubre). Human Rights Law Clinic. http://www.sussex.ac.uk/schrr/ clinic/papers

Winkler, E. (2019, 25 de octubre). Clinical Legal Education: a report on the concept of law clinics. https:/law. handels.gu.se/digitalAssets/1500/1500268_law-clinic-rapport.pdf

Yale Law School (2019, 25 de octubre). Our clinics. de https://law.yale.edu/clinics/our-clinics 